Illinois State University

ISU ReD: Research and eData

Theses and Dissertations

$2-25-2020$

\title{
A Qualitative Study of the Genesis of a Community Food Pantry for Students of Higher Education
}

Elizabeth Fast

Illinois State University, lizziquick@outlook.com

Follow this and additional works at: https://ir.library.illinoisstate.edu/etd

Part of the Human and Clinical Nutrition Commons, and the Public Health Education and Promotion Commons

\section{Recommended Citation}

Fast, Elizabeth, "A Qualitative Study of the Genesis of a Community Food Pantry for Students of Higher Education" (2020). Theses and Dissertations. 1208.

https://ir.library.illinoisstate.edu/etd/1208

This Thesis is brought to you for free and open access by ISU ReD: Research and eData. It has been accepted for inclusion in Theses and Dissertations by an authorized administrator of ISU ReD: Research and eData. For more information, please contact ISUReD@ilstu.edu. 


\section{A QUALITATIVE STUDY OF THE GENESIS OF A COMMUNITY FOOD PANTRY \\ FOR STUDENTS OF HIGHER EDUCATION}

\section{ELIZABETH FAST}

\section{7 pages}

Objective: The purpose of this case study was to understand the development of a food pantry for students of higher education at a Midwestern university.

Methods: The researchers recruited 11 individuals on the food pantry's board using a snowball sampling method to participate in a 30-minute interview about the food pantry's development from conception to implementation. The interviews were transcribed and then qualitatively analyzed by two researchers. The researchers coded interviews separately to identify frequent commonalities between participant responses. The researchers then organized the codes into themes, which were then summarized in the results of this study.

Results: The first research question of this study sought to understand who the key stakeholders in the food pantry program were, and the results concluded those who had personal value and had attention directed towards food insecurity in their community. The second research question focused on the development of the program to understand what guided the decisions made by the founding members of the board and from these questions the themes of network, mentorship, and student leadership emerged. The third focus of this study was to examine the challenges that were encountered during the development of the food pantry program and the outcome was the themes of access, transitional structure, and temporary solution. 
Conclusion: The School Street Food Pantry brought together the representatives from all the stakeholders to organize a solution to food insecurity among students of higher education, albeit a temporary solution. By combining their expertise, experience, and personal values, the School Street Food Pantry's board was able to develop a program that serves over 100 students each week.

KEYWORDS: food pantry; food bank; students; food insecurity 


\title{
A QUALITATIVE STUDY OF THE GENESIS OF A COMMUNITY FOOD PANTRY \\ FOR STUDENTS OF HIGHER EDUCATION
}

\author{
ELIZABETH FAST
}

\author{
A Thesis Submitted in Partial \\ Fulfillment of the Requirements \\ for the Degree of \\ MASTER OF SCIENCE \\ Department of Family \& Consumer Sciences \\ ILLINOIS STATE UNIVERSITY
}


(C) 2020 Elizabeth Fast 


\title{
A QUALITATIVE STUDY OF THE GENESIS OF A COMMUNITY FOOD PANTRY \\ FOR STUDENTS OF HIGHER EDUCATION
}

\author{
ELIZABETH FAST
}

COMMITTEE MEMBERS:

Julie Schumacher, Chair

Jennifer Banning

Amy Bardwell

Jacqueline Lanier

Teresa Drake

Rachel Vollmer 


\section{ACKNOWLEDGMENT}

I'd like to thank my family for their support throughout my graduate experience and for being the voice of reason or alternatively the kick in the pants when I needed it. And similarly, thanks to my friends from undergrad who were never more than a call or text away and kept me sane during these past two years.

Also thank you to my thesis committee, especially Dr. Julie Schumacher and Dr. Jennifer Banning, for volunteering to take part in my research. I wouldn't have known where to start or been able to get to the finish without your guidance and consistent involvement in my thesis. Thank you for sticking with me.

And of course, thank you to the individuals who agreed to be interviewed. I had never done anything like that before but because of your graciousness and passion for the School Street Food Pantry and the students you serve, those interviews were my favorite part of the process.

E.F. 


\section{CONTENTS}

Page

ACKNOWLEDGMENT

CHAPTER I: INTRODUCTION 1

Purpose of the Study 4

Methodology 5

$\begin{array}{ll}\text { Setting } & 5\end{array}$

$\begin{array}{ll}\text { Participants } & 6\end{array}$

$\begin{array}{ll}\text { Procedure } & 6\end{array}$

$\begin{array}{ll}\text { Qualitative Analysis } & 7\end{array}$

$\begin{array}{ll}\text { Results } & 7\end{array}$

$\begin{array}{ll}\text { Personal Value } & 7\end{array}$

$\begin{array}{ll}\text { Attention } & 8\end{array}$

$\begin{array}{ll}\text { Network } & 8\end{array}$

$\begin{array}{ll}\text { Mentorship } & 9\end{array}$

Student Leadership $\quad 9$

$\begin{array}{ll}\text { Access } & 10\end{array}$

$\begin{array}{ll}\text { Transitional Structure } & 11\end{array}$

$\begin{array}{ll}\text { Temporary Solution } & 11\end{array}$

$\begin{array}{ll}\text { Discussion } & 12\end{array}$

$\begin{array}{ll}\text { Personal Value } & 12\end{array}$

$\begin{array}{ll}\text { Attention } & 13\end{array}$

$\begin{array}{ll}\text { Network } & 14\end{array}$ 
$\begin{array}{ll}\text { Mentorship } & 14\end{array}$

$\begin{array}{ll}\text { Student Leadership } & 15\end{array}$

$\begin{array}{ll}\text { Access } & 15\end{array}$

$\begin{array}{ll}\text { Transitional Structure } & 16\end{array}$

$\begin{array}{ll}\text { Temporary Solution } & 16\end{array}$

$\begin{array}{ll}\text { Limitations and Future Research } & 17\end{array}$

$\begin{array}{ll}\text { Conclusion } & 17\end{array}$

CHAPTER II: EXTENDED LITERATURE REVIEW 19

Food Security in the United States 19

Prevalence in the United States 19

Characteristics of Food Insecure Households 20

Causes and Consequences of Food Insecurity 20

Interventions for Food Insecure Households 22

Food Security Among Students of Higher Education 23

$\begin{array}{lr}\text { Prevalence } & 23\end{array}$

Characteristics of Food Insecure Students 24

Causes and Consequences for Students and Higher Education

$\begin{array}{lr}\text { Institutions } & 25\end{array}$

Interventions for Food Insecurity among Students 26

$\begin{array}{ll}\text { Food Pantry Programs } & 27\end{array}$

Target Populations, User Characteristics, and Stakeholders 27

Organization and Design 28

Food Pantry Programs Among Students of Higher Education 29 
Organization and Design Unique to Serving Student

Populations 29

REFERENCES

APPENDIX A: INTERVIEW QUESTIONS 36 


\section{CHAPTER I: INTRODUCTION}

Food insecurity, as defined by the United States Department of Agriculture, can range from a decrease in the quality, variety, or desirability of the diet to disrupted eating patterns and reduced food intake (Coleman-Jensen, Rabbitt, Gregory, \& Singh, 2019). Food insecurity affects $11.1 \%$ of households in the United States nationwide, leaving many families susceptible to poor diet quality (Coleman-Jensen et al., 2019). In Illinois, the prevalence of food insecurity is not significantly different from the national average, with $10.7 \%$ of households classified as food insecure and $4.4 \%$ as having very low food security (VLFS) (Coleman-Jensen et al., 2019). That percentage may be even higher among college students, up to one-third of the population, especially given the financial instability and unique living conditions that many students face. In some studies, up to $48 \%$ of college students were classified as food insecure (Coleman-Jensen et al., 2019; Payne-Sturges, Tjaden, Caldeira, Vincent, \& Arria, 2017; Twill, Bergdahl, \& Fensler, 2016; Zein, Mathews, House, \& Shelnutt, 2018). Students may also lack basic food literacy, further preventing them from providing themselves with a healthy diet (Watson, Malan, Glik, \& Martinez, 2017).

Food insecurity can contribute to a decline in health, especially when combined with other stressors like pressure from school, work, and relationships (Leung, Epel, Ritchie, Crawford, \& Laraia, 2014; Holben \& Marshall, 2017). Food insecurity puts both the students and their schools at risk. Data on students of higher education are not as extensive when compared to the K-12 population, but repercussions of food insecurity are similar among both groups (Gallegos, Ramsey, \& Kai, 2014; O’Neill \& Maguire, 2017; Silva et al, 2017). This is concerning for colleges, noting that K-12 students who lived in food insecure households are more likely to have lower math and reading scores, have memory deficits and behavioral 
problems, and drop out before graduation (Broton \& Goldrick-Rab, 2018). Food insecurity also has negative effects on health status; those who are food insecure are more likely to be obese or overweight (Twill et al., 2016). Food insecure students are more likely to self-report depression symptoms, showing that the effects are mental as well as physical (Payne-Sturges et al., 2018). The consequences of food insecurity should be concerning to the administration of higher education institutions, whether for altruistic reasons, such as higher GPAs, or more selfinterested reasons, such as retention rates (Buch, Langley, Johnson, \& Coleman, 2016).

The population of university students is widely varied, including full and part-time students, undergraduate and graduate students, and residential and commuter students. However, they have several financial commonalities including restricted ability to work and earn wages while simultaneously paying tuition and other education-related expenses (Twill et al., 2016). While measures should be taken to resolve these larger, underlying issues, interventions are needed in the meantime to address the issue of food insecurity among college students.

Colleges and universities are not ignorant of the implications of food insecurity. Many have recently begun taking steps to combat the issue in their student bodies, starting by conducting surveys to assess the severity of food insecurity (Buch, 2016; Broton, 2018; Knol, 2017; Payne-Sturges, 2018; Twill et al., 2016; Zein et al, 2018). These studies cited varied reasons for food insecurity, including rising costs of both tuition and living expenses, restricted income, and lack of practical food preparation skills (Broton \& Goldrick-Rab, 2018; Buch et al., 2016; Knol, Robb, McKinley, \& Wood, 2017; Watson et al., 2017).

Tuition has increased dramatically in recent years at both public and private universities alike even when considering financial aid and federal assistance, which has overall decreased (Broton \& Goldrick-Rab, 2018). Moreover, a rising number of students come from low-income 
backgrounds or are the first generation in their families to attend university (Broton \& GoldrickRab, 2018). All these factors lead to the average student having higher costs for education while having fewer resources to build on as a foundation. Many students must seek additional sources of income, but employment may not make a big enough difference to prevent food insecurity (Knol et al., 2017). In a series of surveys including 30,000 students at 121 colleges across 26 states, the percentage of employed students was not significantly different between those who were identified as food insecure and those who were not (Knol, 2017).

A previous study examined the factors that contribute to food insecurity among college students. Students may not self-identify as food insecure if they perceive it as normal or are unfamiliar with the term, preventing them from looking for resources in the first place (Watson et al., 2017). Additionally, researchers found that barriers to use a pantry can prevent students from utilizing the resources even if they are aware of their availability (Zein et al., 2018). Food insecurity was more likely to be experienced by students that lived off campus as compared to students that lived in on-campus housing (Twill et al., 2016). Many times, students who choose to live in their own housing are establishing their household for the first time which makes them vulnerable because they may not have skills to balance a budget or prepare healthy inexpensive meals, which can contribute to the development of food insecurity (Twill et al., 2016; Watson et al., 2017). Food-insecure students may also be unaware of resources available to them or their eligibility, whether they be school-sanctioned organizations or federal aid programs such as the Supplemental Nutrition Assistance Program (SNAP) (Knol et al., 2017).

Some universities have responded to food insecurity by developing food pantries as a resource for their students (Broton \& Goldrick-Rab, 2018; Buch et al., 2016; Zein et al., 2018). In the process of creating food pantries, organizers found that the partnership of many 
constituents, such as administration, donors, current students, and on-campus organizations, is invaluable to support the starting and ongoing needs of a food pantry program (Buch et al., 2016). Even if food pantries are well-organized and operating smoothly, it may be difficult to assess if the right population is being reached by a food pantry (Broton \& Goldrick-Rab, 2018). While a survey reported that the majority of its clients were considered at risk, many were repeat visitors, indicating that they were not reaching many new clients who qualified for assistance (Buch et al., 2016).

Even if students realize they are food insecure and are aware of resources, they will have to overcome barriers to utilize a food pantry, including social stigma associated with receiving assistance, insufficient information regarding eligibility and use of the pantry, and limited hours that may be inconvenient for busy students (Zein et al., 2018). Instead of relying on outside sources for assistance, some students may develop coping mechanisms to deal with insecurity, such as skipping meals (Watson et al., 2017).

\section{Purpose of the Study}

Higher education creates a unique conundrum: in the pursuit of improving their socioeconomic status, some students fall even further down the ladder to the point of dealing with food insecurity. Colleges and universities have begun to recognize the need of their students and implement strategies to address the issue, including food pantries. However, research is needed to identify common issues during the development of a food pantry program and ways to overcome those issues, as well as helpful or essential resources to maintain a successful program that can decrease the prevalence of food insecurity among students of higher education. 
The purpose of this case study was to understand the development of a food pantry for students of higher education at a Midwestern university. The research questions that guided this study included:

1) Who were the key stakeholders in the development of the School Street Food Pantry?

2) What decisions were made in the development of the structure of the School Street Food Pantry?

3) What challenges were encountered in developing the School Street Food Pantry?

\section{Methodology}

\section{Setting}

The School Street Food Pantry is a non-profit program that provides students in the local community with food, supplies, and other resources with the goal of alleviating food insecurity. The food pantry was developed in part by using the toolkit created by the Student Government Resource Center (2015). The program receives its not-for-profit status from the First United Methodist Church that also provides their facility for operations, conveniently located adjacent to one of the major university campuses served by the pantry. Despite having several connections to the campus community, the program does not have an official affiliation with a university. The food pantry is in its second year of operation and serves over 100 students per week.

The board of the food pantry is entirely volunteer-based, consisting of local students, university faculty and staff, and community members. At the time of this study, the board had not defined roles for board positions, although the board members had specific duties assigned to them and, in some cases, associated titles. Moving forward the board intended to define positions and develop policies to provide a consistent structure and expectations to benefit both the program's volunteers and participants. 
The food pantry receives supplies from the Midwest Food Bank and the Eastern Illinois Food Bank as well as individual donations and food drives. Distribution of hygienic supplies and food, including perishables and produce, occurs for two hours each week, during which students are allowed to select their own choices, filling a number of bags determined by household size. User eligibility is determined by presentation of a valid student ID. No other requirements are needed.

\section{Participants}

The participants of this study were gathered using the snowball sampling technique, beginning with current board members of the food pantry program. The School Street Food Pantry had not defined or qualified positions on their board at the time of this study although it consisted of those who volunteered to serve in a leadership role in the program. The board consisted of approximately 20 individuals, including students at Illinois State University and members of the larger local community. The members of School Street Food Pantry's board received an email invitation to participate in the study and were also asked to recommend other relevant candidates who assisted in starting and planning the food pantry program. The researchers recruited 11 individuals using this sampling method. The researchers determined that once saturation of the data was achieved, recruiting stopped. Each candidate received a $\$ 20$ Target gift card for participating. Before the study began, approval was obtained from the Institutional Review Board at Illinois State University.

\section{Procedure}

Each participant was invited to an individual interview that was scheduled at their convenience in a private location of their preference. The same researcher conducted each interview, which consisted of open-ended questions regarding the development of the food 
pantry program. Interview questions were derived from the research questions presented in this study's initial proposal and approved by the committee members. Each semi-structured interview was audio recorded and lasted an average of 30 minutes. Once the interview portion of the study was completed, the audio recording was transcribed. The content of the interview transcripts was then qualitatively analyzed by two researchers.

\section{Qualitative Analysis}

In qualitative analysis, the researchers coded interviews separately to identify commonalities. Of the 11 interviews completed, two interviews were compared to determine interrater reliability with a standard of $80 \%$ agreement between codes (Creswell, 2007). Once the interviews were coded and interrater reliability was determined, the codes were organized into themes, which were then summarized in the results of this study, interpreting and explaining the themes that emerged in the development of the food pantry program. Finally, the findings were related to applications and future research.

\section{Results}

The first research question of this study sought to understand who were the key stakeholders in the food pantry program. In this study, stakeholders were defined as any person with an interest or concern in the program. A few themes emerged from interviewing the core leadership of the pantry that addressed this question: personal value and attention.

\section{Personal Value}

The leadership of the program had a sense of personal value when dealing with food insecurity among students of higher education because they were all stakeholders in the program's success. Some had experienced it themselves as students, others had children or friends that were students experiencing food insecurity. As one student leader said, "it's a 
personal value thing that I think that we should be providing to those who are in need... if we can do this, we should do this." Furthermore, "there's not a monetary incentive [for those running the program]. So what we're doing is much more of a community building aspect."

\section{Attention}

Interviewees frequently stated that those who would benefit from the success of the program were not always aware of the potential profits. First, the founders realized it was critical to generate attention that the program existed for the population in need. According to one community board member, "there were some disconnects between the students and some of the resources that are available." But even before that, the food pantry's founders had to draw attention from the general community that the issue of food insecurity existed among students of higher education. According to a community leader, "there's just been a long awareness of the need." But as one student board member said, "we had to generate numbers that supported the claim that we were making, which was that this issue exists." Thus while there is recognition of the need, some board members felt that it was not widespread in the community.

The second research question focused on the development of the program. Through the interviews, the researcher sought to understand what guided the decisions made by the founding members of the board, which consisted of both community and student leaders. From these questions, the themes of network, mentorship, and student leadership emerged.

\section{Network}

Building a food pantry program from scratch required the investment of several parts of the larger community. As one interviewee said, "There was a nice big coordinated effort with [the township]... members of the church have become very invested... student leaders have become very invested... and the right people came together." Those three groups - the general 
community, the students, and the church - where often cited by other interviewees as both stakeholders in and contributors to the program's early success. This came about because of a few key individuals who were able to bring diverse groups together. These included a member of the area township and a retired university faculty member, the former having encountered individuals in the community who were attentive to the issue of food insecurity and the latter being similarly connected within the university. One board member explained, "initially, having networked people was important, because of making the connections both within [the university] and the community."

\section{Mentorship}

When it came to making decisions about the structure of the food pantry, the founders looked to those who had experience. Many of these mentors came from the community, because "we were lucky enough to be in a community where those people... those organizations already existed." Another interviewee expounded on this, saying they "really [used] the expertise of our outside folks to say, this has worked in other settings, you might want to try this." Experienced mentors were useful with the minutiae of regular operations, such as how to approach distribution, as well as recognizing the importance of the establishment of board-approved policies and procedures to solidify the organizational structure.

\section{Student Leadership}

As one community board member said, it was a priority that "everything is to be very student-driven... students helping students is really important." However, it was difficult at times for these individuals because of the workload as a student and a member of the pantry's board was significant, and that was where mentorship from community members on the board could pick up the slack. A student leader explained, "we had a big problem with overworking or stress 
for people [who are] in the process of finishing their degrees, and having a whole bunch of other things." Despite this challenge, students were an intrinsic and invaluable part of the development process by providing motivation from their personal value as well as introducing new ideas stemming from their perspective as the target population. Thus by including both students and community members in the board, the students who had other responsibilities benefited while still being able to bring their experience to the decision-making process.

The third focus of this study was to examine the challenges that were encountered during the development of the food pantry program. While most interviewees initially denied challenges, a few themes emerged that spoke of struggles that occurred during development and operation of the program. These themes were coded as access, transitional structure, and temporary solution.

\section{Access}

The importance of accessibility to the food pantry's services were brought up by several of the interviewees. While the program may have resources to offer, if they are not available to the target population in a format that is usable and beneficial to clients, the program is not addressing the need, and this goes beyond the physical aspect of access such as ADA compliance of the space or proximity to campus. As a student leader on the board said, “....we want to be a partner, and not dictate what is appropriate for someone else." Similarly, another board member said, "the idea of food dignity, while utilizing the pantry is great," in reference to the board's decision to make the pantry a selective program where users could choose which food items to take. This was part of another effort to make the food pantry more accessible was by reducing stigma. The inclusion of students, the target population, both on the board and as regular volunteers also reduced stigma by exposing and familiarizing them with the mission and 
operation of the food pantry. This meant taking a step back and assessing the characteristics of the post-secondary students and understanding their specific needs, as a student leader said, "When we got started... we were kind of seeing, is this going to be appropriate for our population?" By asking for feedback from the food pantry users, they were able to roughly assess the effectiveness and utility of the program and make decisions and adjustments from that feedback.

\section{Transitional Structure}

The food pantry's board and regular [employees] are all volunteers, which has advantages and disadvantages. Originally, it was difficult to have a formalized structure because the board was built on a volunteer basis. As one student leader said, "they're willing, and we all agree that this person, you know, is a good fit for the spot. So the structure was very fluid." A lack of rigidity worked to get the program off the ground by allowing adaptation to overcome the initial challenges. However, several members, especially the mentors on the board, felt a more defined structure would carry the program forward rather than allowing it to be hampered by inconsistency in operations and leadership. The food pantry board has been trying to address this; as one member said, "a lot of this will get easier if they have these things written down. Like this is our policy... This is what we do."

\section{Temporary Solution}

Many of the interviewees recognized that the food pantry is only a temporary measure. The underlying issue of food insecurity will still exist despite how many people are served or how much food is distributed. As one student leader said, "By having open distribution hours, two hours each week, you know, I don't think that's going to fix the problem." Furthermore, the problem of food insecurity is multifactorial. A community member on the board also recognized 
this issue, stating that through the food pantry program "you're not addressing the other side of that sentence, which is, housing costs are ridiculous, but you know, one thing at a time." The program has tried to address this conundrum by offering additional services outside of food distribution, such as cooking classes. A faculty leader on the board said, "the connections we have... have allowed the users of the pantry to be aware of other social services here in the area," to address food insecurity. Still, according to another board member, "the purpose of the food pantry is to be a stop gap for people who are hungry."

\section{Discussion}

While previous studies have surveyed the client populations of food pantry programs or examined the needs of that population, minimal studies have documented the process of building a program that can effectively serve post-secondary students who are food insecure.

\section{Personal Value}

For any kind of initiative, one of the most difficult barriers to overcome is inertia. If the food pantry founders did not have an intrinsic motivation to pursue this program, it likely would not have made it past the conceptual stage of development. The Student Government Resource Center (SGRC) recommends that the steering committee be comprised of individuals from different segments of the campus community with interest in hunger relief (2015). The School Street Food Pantry excelled at this by bringing together a diverse group of leaders not only within the campus community but in the surrounding community who would later prove invaluable to the food pantry's development. With the prevalence of food insecurity being much higher among students of higher education than the general population, it is not surprising that 
many founding members had experienced food insecurity or knew someone who had while they were a student (Halfacre, Chang, Roseman, \& Holben, 2017; Knol et al., 2017; Patton-Lóez, López-Cavellos, Cancel-Tirado, \& Vazquez, 2014; Twill et al., 2016). Therefore, the School Street Food Pantry's experience indicates that the additional effort of including steering committee members from beyond the campus community yields excellent return.

\section{Attention}

While individuals who are experiencing food insecurity may be aware of the issue, the general community may not realize how much food insecurity is affecting its members. Generating attention for the issue can provide support and resources to both the individuals in need and the programs seeking to serve them. The student government conducted a survey of the student body at the primary university regarding food insecurity to gather data to clarify the need for intervention, which is recommended (Student Government Resource Center, 2015), although the food pantry is not a student government initiative. Throughout development, the School Street Food Pantry has had to work consistently to draw attention to food insecurity and their service, which includes collecting data from food pantry users. Like most initiatives, this program required marketing to highlight the issue and reach the target population with their response, which is not unique among food pantry programs (Berry, Sloper, \& Doll, 2019; Vaterlaus, Martineau-Cottle, Vaterlaus-Patten, \& Gibbons, 2018). Marketing included media such as radio and local publications as well as flyers and signage (Student Government Resource Center, 2015). As one board member pointed out, "it wasn't just enough that we were there in the room making the decisions and putting it together, we had to actually announce that we exist." Generating attention through multiple avenues, while having data to validate their necessity, allowed them to connect food insecure students with the service they were offering. 


\section{Network}

As attention is critical for supplying the support needed to build a food pantry program, network is essential for coordinating that support. The Student Government Resource Center toolkit stresses the importance of establishing partnerships with key institutions, including the food bank, student government, and university administration (2015). However, the School Street Food Pantry relied more on community support and has not yet made an official affiliation with a university. Despite the lack of recognition, the program still draws on individual faculty and staff for assistance and might have benefitted from official support from university administration in multiple aspects, whether funding, publicity, or other resources. Instead, this program relied on a partnership of key individuals who were able to bring together the resources - facilities, volunteers, and supply sources - that allow the program to function successfully. Partnerships are essential if a program is to accomplish all the necessary steps to be successful (Berry et al., 2019) and for this food pantry program, that network brought together students, faculty and staff, and community members.

\section{Mentorship}

Part of the food pantry program's network included mentors, individuals who had experience or knowledge to bring to the table. These included individuals who had either worked in similar programs or who had worked with issues unique to the target populations. They were able to provide guidance to the program which allowed the founders to sidestep some barriers as well as develop an effective structure. Interestingly, the Student Government Resource Center toolkit does not mention the value of seeking out mentors but instead emphasizes establishing supportive rather than guiding relationships (2015). For the School Street Food Pantry, they were 
able to take what these mentors had already learned and observed being implemented elsewhere to develop a framework to start with (Reppond, Thomas-Brown, Sampson, \& Price, 2018).

\section{Student Leadership}

Student leadership was one of the strongest aspects of this program. Students strengthened the program in many ways, including bringing a powerful contribution of personal value from their own experiences. They also brought a large portion of energy and innovation that neatly counterbalanced the tested methods presented by the program's mentors. While the Student Government Resource Center toolkit is centered around student initiative and leadership, it also expects strong support from the affiliated universities and relevant student organizations in an official capacity, which the School Street Food Pantry did not have. Often, similar programs at other universities are initiated and developed by faculty and staff (Reppond et al., 2018); whereas this program brought together students, university employees, and community members. However a student-focused food pantry originates, students should be an intrinsic part of the program's leadership along with qualified mentors, perhaps students from other universities with successful programs.

\section{Access}

The idea of accessibility for pantry users was a core value for several of the founders and they recognized it was an area for improvement. By including students in the development, they could provide input about what was feasible for their peers. Ideas for increasing access included expanding the hours of distribution, diversifying the products offered, and allowing individuals to choose what was appropriate for themselves. The School Street Food Pantry sought the input of its users to determine how best to increase accessibility. This is encouraged in the Student Government Resource Center's recommendations by conducting ongoing surveys (2015). 
Student populations have unique traits, so identifying their unique barriers is critical to become an effective resource (Berry et al., 2019; Reppond et al., 2018; Vaterlaus et al., 2018). Another important factor of access is diminishing stigma surrounding "welfare programs" like food pantries (Vaterlaus et al., 2018). This program sought to relieve the stigma through food dignity, allowing food pantry users to shop the items that were available, and exposure, as many of the food pantry's volunteers were students who could utilize the program themselves. Improving access is an ongoing challenge that needs constant identification and problem-solving to overcome.

\section{Transitional Structure}

Initially the food pantry program's leadership structure was fluid, taking on whoever was willing to assist in developing the program. While this structure arose organically, this is somewhat contradictory to the Student Government Resource Center's emphasis on extensive planning and structuring prior to launching operations (2015). However, this flexibility was helpful in allowing them to adapt as individuals' commitments changed, but in the long term, a more stable structure will be needed to sustain the program through the years. The leadership recognized this and began to create a more defined board and set policies to provide a steady foundation for the program to grow.

\section{Temporary Solution}

While the consensus from the interviews was that a food pantry program was needed, many of them pointed out that the underlying problems that cause food insecurity would not be solved by this program. Despite that, they believed the food pantry could make a difference, even if it was only a stop gap. As one board member said, "we generate a conversation that might lead to solving the problem, or at least, aiming to fix it." Even if they do not solve the cause of the 
problem, food pantries have been shown to alleviate food insecurity (Nguyen, Shuval, Bertmann, $\&$ Yaroch, 2015). In this way, the leaders of the School Street Food Pantry are visionaries who seek to extend their impact and look beyond the limited influence of the program on diminishing food insecurity among students of higher education. This self-awareness will further push the program to grow and evolve as it seeks to truly alleviate food insecurity.

\section{Limitations and Future Research}

This study was limited due to the sampling method, which used a snowballing approach to produce a convenience sample from the members of the board who responded to the invitation email. The study also used an unpiloted questionnaire applied to a semi-structured interview format that may have reflected the researchers' biases towards the research questions. While these limitations are acknowledged, the study coordinators deemed them acceptable given the type of research being conducted.

In future research with this program, it would be interesting to do a follow up study to reassess the program once it has had time to settle. Another opportunity for research would be to observe the benefits and effectiveness of this program in addressing the issue of food insecurity among its target population, such as interviews with the clients of the food pantry. It would also be informative to perform a comparative longitudinal study on the effects of participating in a food pantry program on student outcomes.

\section{Conclusion}

The results of this study are relevant to health and nutrition professionals and social workers involved with student populations. While a food pantry may not be able to resolve food insecurity among students of higher education, dietitians and public health workers are uniquely suited to fill the mentorship role opposite the student leadership in the dynamic that proved 
successful for the School Street Food Pantry. These professionals can partner with students to alleviate food insecurity through these programs either by initiating or supporting them. This applies to faculty, staff, and administrators of universities and colleges too, as their work is intimately tied to the student body. Food insecurity influences the health and therefore the performance of the affected population (Gallegos et al., 2014; Holben \& Marshall, 2017; Leung et al., 2014; Nguyen et al., 2015; O’Neill \& Maguire, 2017; Silva et al., 2017), which concerns professionals in public health and, for student populations, the institutions where they are enrolled.

The School Street Food Pantry was successful in many aspects, although there is plenty of room for growth. The program brought together the representatives from all the stakeholders to organize a solution to food insecurity among students of higher education, albeit a temporary solution. By combining their expertise, experience, and personal values, the School Street Food Pantry's board was able to develop a program that serves over 100 students each week. 


\section{CHAPTER II: EXTENDED LITERATURE REVIEW}

\section{Food Security in the United States}

\section{Prevalence in the United States}

In the United States, food security is a persistent concern touching many communities and populations. The United States Department of Agriculture created a definition for food insecurity, which states that food insecurity can range from a decrease in the quality, variety, or desirability of the diet to disrupted eating patterns and reduced food intake (Coleman-Jensen et al., 2019; Holben \& Marshall, 2017). To be classified as food insecure, a household must indicate that at least three or more food-insecure conditions were met within the past year on the Current Population Survey Food Security Survey. Furthermore, "households in which the food intake of one or more members was reduced and eating patterns disrupted because of insufficient money and other resources for food" have Very Low Food Security (VLFS) (Coleman-Jensen et al., 2019).

It is important to note that food insecurity is not a constant but rather a cyclical or recurrent condition (Coleman-Jensen et al., 2019). Food insecurity is also distinct from the issue of hunger, although both have repercussions that affect behaviors of daily living. Hunger is a physiological response to insufficient nutrition. Food insecurity is a psychological condition of a perceived insufficiency due to lack of funds or resources (Holben \& Marshall, 2017).

According to a position paper by the Academy of Nutrition and Dietetics, "access to enough food for an active, healthy life, is a basic human need and fundamental right" (Holben \& Marshall, 2017). However, as of 2018, 11.1\% of households in the United States were classified as food insecure and overall 4.3\% were classified as VLFS households (Coleman-Jensen et al., 2019). Although food security remains an ongoing concern, the prevalence of food insecurity in 
the United States has been declining since it peaked in 2012 following the economic recession in 2008 (Coleman-Jensen et al, 2019).

\section{Characteristics of Food Insecure Households}

Certain subpopulations are more likely to experience food insecurity than the general population. Among households with children, 13.9\% experienced food insecurity in 2018. Because of coping mechanisms that develop in these households, approximately half of them experienced food insecurity that affected the children's dietary intake or quality (ColemanJensen et al, 2019). In an Australian study, 25.5\% of households with students in tertiary education were food insecure (Gallegos et al., 2014). Thus, while not all households with dependents are food insecure, it is a common characteristic.

Food expenditure is another disparity that exists between households that are food secure and those who are not. As of 2018, food secure households spent 21\% more on food purchases than those that were food insecure. In food secure households, the average food expenditure per person was $\$ 50$ per week, while in food insecure households the average was $\$ 43.33$ per person (Coleman-Jensen et al., 2019). Although food insecure households spend less on food than the general population, more of them are enrolled in a federal assistance program. As of $2018,56 \%$ of food insecure households were receiving assistance from programs including the Supplemental Nutrition Assistance Program (SNAP), the Special Supplemental Nutrition Program for Women, Infants, and Children (WIC), or the National School Lunch Program (NSLP) (Coleman-Jensen et al., 2019).

\section{Causes and Consequences of Food Insecurity}

While there are several conditions that are observed in association with food insecurity, research has yet to determine a direct cause-and-effect relationship, if such a relationship exists. 
Rather, these elements could be working in reciprocity to contribute to an overall deterioration of the affected individual's status. Food insecurity touches many aspects of the affected individual's life, but perhaps the most logical one is dietary quality. Because food insecurity is episodical in nature, it can lead to erratic dietary patterns and decreased diet quality (Holben \& Marshall, 2017; Nguyen et al., 2015). Nguyen et al. (2015) found that food insecurity causes increased intake of overall calories, added sugar, and empty calories. Using National Health and Nutrition Examination Survey (NHANES) data, Leung et al. (2014) found that food insecurity negatively affected diet quality even when assessed in multiple ways, including food groups, individual foods, specific nutrients, diet quality scores, and meal occasions. Food insecure individuals consume more full-fat dairy, red and processed meats, salty snacks, and sugar-sweetened beverages, as well as nuts, seeds, and legumes, which could be because they are a more affordable protein choice. Conversely, intake of fruits and vegetables was diminished (Leung et al., 2014). From the NHANES data, inadequate nutrient intakes for food insecure individuals was vitamin E, essential fatty acids EPA and DHA, and carotenoids.

Similarly to poor diet quality among food insecure individuals, poor health outcomes are well-documented, extending to the point of malnutrition (Leung et al., 2014, Holben \& Marshall, 2017). Food insecurity is also predictive of 10 chronic diseases, including increased risk of obesity in adults, while income is only predictive of three (Holben \& Marshall, 2017; Nguyen et al., 2015). Those who seek food assistance may be aware of the risk of obesity and other chronic diseases (Dave, Thompson, Svendsen-Sanchez, \& Cullen, 2017). These health issues may in turn increase the likelihood of food insecurity, contributing to a downward spiral (Holben \& Marshall, 2017). 
Because food insecurity has a psychological element, it can affect mental health in addition to physical health. Leung et al. (2014) found that food insecurity is a stressor even when controlling for poverty. While food insecurity can contribute to mental health issues, mental health can also precipitate food insecurity by increasing the burden on vulnerable individuals and households (Holben \& Marshall, 2017).

Households experiencing food insecurity have various coping mechanisms, some more ideal than others. Coping mechanisms include purchasing less expensive, calorie-dense options or damaged products, consuming products past the expiration date, and watering down food and beverages (Weinfeld, Malan, Glik, \& Martinez, 2014). While these strategies may alleviate the immediacy of hunger, they do not solve the issue of providing nutritional adequacy or a healthful diet.

\section{Interventions for Food Insecure Households}

While the cause of food insecurity cannot be isolated to just a few contributing factors, interventions can target some known issues or at least provide stop-gaps for those who experience food insecurity. SNAP is a federal income assistance program that works to alleviate food insecurity and hunger, albeit with inconsistent results. A study found that SNAP improved Healthy Eating Index-2010 (HEI) scores and body mass index (BMI) among food insecure individuals (Nguyen et al, 2015). However, SNAP also diminished diet quality and increased obesity among adults, independent of food security status (Nguyen et al, 2015). The Commodity Supplemental Food Program (CSFP) is another federal program that provides relief to those aged 60 and over who are below $130 \%$ of the federal poverty line. A study of the CSFP showed a diminished severity of food insecurity among individuals participating in the program (Khan, Schiff, \& Mello, 2019). 
Food pantries that are run by private organizations can also provide a source of relief for those experiencing food insecurity; however, their effectiveness can vary. Depending on the program, their services may not be enough to completely alleviate food insecurity between visits, whether that be monthly or weekly (Bazerghi, McKay, \& Dunn, 2016). The ones that are most effective tend to promote food dignity, which allows food pantry users to have input on what items they receive. Food dignity also can mean having culturally appropriate and suitable foods available for food pantry users (Bazerghi et al, 2016). Still, these programs represent stop gaps rather than permanent solutions, and their overall impact can be difficult to quantify because the populations that attend food pantry programs are not food insecure by default.

\section{Food Security Among Students of Higher Education}

\section{Prevalence}

While the USDA has not collected nationally representative data on food security among students of higher education, many independent studies have indicated food insecurity is much more prevalent among students than the general population. A study at a university in Oregon found that $59 \%$ of their students were food insecure; similarly, $48 \%$ at a university in Ohio, $46 \%$ at a university in Mississippi, and 37\% at a university in Alabama (Halfacre et al., 2017; Knol et al., 2017; Patton-Lóez et al., 2014; Twill et al., 2016). Another study focused on several urban and suburban community colleges and found that $56 \%$ of the students had either food insecurity or VLFS. Although the prevalence varies between schools, all food insecurity rates are significantly higher than the national average. While food insecurity among students may be temporary or recurrent, similar to the general population, food insecurity still has negative outcomes for those affected (Lee et al., 2018). 


\section{Characteristics of Food Insecure Students}

Like the general population, certain subgroups of students are more likely to experience food insecurity than others. Minorities, including African American, Hispanic, Asian, and Indigenous individuals, are more likely to be classified as food insecure than White individuals (Lee et al., 2018; Maroto, Snelling, \& Linck, 2015; Twill et al., 2016). Gender also affects the likelihood of food insecurity, with women more often being food insecure (Lee et al., 2018; Twill et al., 2016).

Housing situation also has a strong association with food security status. Students of higher education who live off campus whether alone, with roommates, with a spouse or partner, or without parents are more likely to experience food insecurity (Gallegos et al., 2014; Lee et al., 2018; Maroto et al., 2015; Twill et al., 2016). A study by Gallegos, Ramsey, and Kai determined students who rented or boarded rather than living at home with parents were 2-3 times more likely to be classified food insecurity (Gallegos et al., 2014). Housing tenure, or how long the student lived in one location, also influenced food security status, with shorter tenure correlated with increased food insecurity (Gallegos et al., 2014).

If a student has a dependent, they are more likely to experience food insecurity. Children are a risk factor for students of higher education to become food insecure, especially if they are single parents (Lee et al., 2018; Vaterlaus et al., 2018). A survey of food pantry users across the United States found that $77 \%$ of students who were single parents were also food insecure compared to $54 \%$ of students who were not parents (Vaterlaus et al., 2018).

Student status is another variable that influences food security. Class standing (undergraduate versus graduate), receiving of financial aid, and first-generation attendance were also correlates associated with food security status (Lee et al., 2018). According to Ellis et al. 
(2017), however, membership in Greek life was not associated with a difference in food security status at a university in Alabama.

Employment status and income are additional factors associated with food insecurity (Gallegos et al., 2014; Lee et al., 2018). Gallegos, Ramsey, and Kai (2014) found that students who are employed part-time, or receive income support or an equity-based scholarship are four times as likely to be food insecure than the general student population. Food insecurity is also associated with reliance on food assistance programs (Lee et al., 2018).

\section{Causes and Consequences for Students and Higher Education Institutions}

When a student is experiencing food insecurity, many aspects of their health - physical, mental, and academic - are negatively impacted. Like the general population, food insecurity is linked to diminished health status and diet quality (Ellis et al., 2017; Knol et al., 2017; Mirabitur, Peterson, Rathz, Matlen, \& Kasper, 2016; Patton-Lóez et al., 2014; Twill et al., 2016). Additionally, food insecurity is significantly associated with poor eating habits, such as decreased mindful eating, diminished response to external cues, and increased meal skipping, with increased responsiveness to biological cues like hunger and satiety (Knol et al., 2017; Twill et al., 2016). Fruit and vegetable intake is diminished among food insecure students (Gallegos et al., 2014; Mirabitur et al., 2016). Furthermore, students are aware of the detrimental effect of food insecurity when asked to report their perception of their health (Ellis et al., 2017; Gallegos et al., 2014; Patton-Lóez et al., 2014).

In a study by O'Neill and Maguire, students who were food insecure reported decreased energy levels and concentration (O'Neill \& Maguire, 2017). Food insecure students (58.6\%) also said that it decreased their ability to attend class and $87.5 \%$ said it decreased their ability to perform in class (Silva et al., 2017). Another study found that food insecure students were three 
times more likely to defer their studies (Gallegos et al., 2014). Some students are aware of the detrimental effects of food insecurity, with $25 \%$ reporting they recognized a correlation with poor academic performance and poor health (O'Neill \& Maguire, 2017).

The diminished academic performance among food insecure students is reflected in their grades. O'Neill and Maguire found that food insecurity was associated with lower GPAs (O’Neill \& Maguire, 2017). Furthermore, Patton-Lóez et al (2014) found that students with a GPA greater than 3.1 were $60 \%$ less likely to be food insecure. In another study, when students were separated into categories based on GPA, those with a GPA between 2.0 and 2.49 were more likely to experience food insecurity than those in the highest bracket of 3.5-4.0 (Maroto et al, 2015).

Food insecurity arises primarily from a lack of financial resources. Over the past couple decades, costs of living and college tuition have risen, which compromises students who choose to pursue higher education (Twill et al., 2016). A study at a university in Mississippi found that student loans were associated with VLFS (Halfacre et al., 2017). Many students choose to seek employment; however that does not decrease the risk of food insecurity (Patton-Lóez et al., 2014, Twill et al., 2016). Patton-Lóez et al. (2014) found that employment was correlated with higher rates of food insecurity, possibly due to lack of financial support from parents or other sources which necessitated employment to meet needs.

\section{Interventions for Food Insecurity among Students}

Students experiencing food insecurity find many ways to cope, and already students, colleges and universities, and the larger community is working to intervene. Some students are eligible for traditional federal assistance programs, although stricter policies may be edging out students (Mirabitur et al., 2016; Twill et al., 2016). Another traditional option is a food bank or 
food pantry program. Patton-Lóez et al. (2014) found that food insecurity is significantly correlated with participation in a food assistance program, although the ability of food pantries to improve food insecurity has not proved as strong. However, it may be a last resort for some and participation can vary between schools, with study results ranging between $5.6 \%$ and $27 \%$ of students seeking food relief (Gallegos et al., 2014; Lee et al., 2018; Patton-Lóez et al., 2014).

In a survey by the Feeding America Network, they reported various ways their affiliated programs provided services to college students. The most common avenues were direct food distribution; assistance with applying for SNAP, whether in-person, over the phone, or through workshops; and policy activities with local, state, federal, and campus governments and administrations (Berry et al., 2019). Other services included referrals to other programs, nutrition education, cooking classes, emergency aid, utilities assistance, housing info assistance; sharing meal plan "swipes;" and providing metro/bus/gas cards (Berry et al., 2019).

\section{Food Pantry Programs}

\section{Target Populations, User Characteristics, and Stakeholders}

While there are many initiatives that work to abolish hunger and food insecurity in the United States, food pantries are one of the most common local efforts that provide relief. Although it is not nationally representative, the Feeding America Network conducted a survey of the clients of their affiliated food distribution programs. They found that they serve 5,300,000 unique clients per week (Weinfeld et al., 2014). Of those, 57\% only held part-time employment, 26.1\% had not graduated high school, and $46.4 \%$ had graduated high school or earned their GED (Weinfeld et al., 2014). 


\section{Organization and Design}

Food pantry programs should be run with consideration of those being served, specifically to meet the needs and wants of the target population (Vaterlaus et al., 2018). When objectives include providing excellent customer service, food pantries are more likely to benefit their clients (Vaterlaus et al., 2018). Examples would include providing food conducive to dietary restrictions (Vaterlaus et al., 2018).

Because stigma exists around utilizing food pantries, programs must consider the social, emotional, and functional dimensions of their services (Vaterlaus et al., 2018). Many barriers exist for individuals who seek assistance from food pantries, including financial uncertainty, cost of healthy foods, lack of time, rationing food within family, lack of transportation, lack of adequate kitchen equipment, lack of nutrition knowledge and skills, and inadequate social support network (Dave et al., 2017). Food pantries may have to extend beyond their central function or partner with other organizations to provide additional services and allow the target population to utilize their program to its full potential.

The most significant challenge food pantry programs face is their effectiveness. Food pantries typically are unable to alleviate the effects of food insecurity in the long- or short-term, especially as many food pantry users are experiencing food insecurity for extended periods (Bazerghi et al., 2016). Ideally, users would not become dependent on a food pantry to sustain their household; rather it would be a one-time emergency resource. Food pantries are generally not conducive to supporting the nutritional requirements of individuals, whether they are food insecure or not (Bazerghi et al, 2016). In a survey of a network of food pantries, $27 \%$ of

programs reported they had less food than was needed (Berry et al., 2019). The food pantry 
programs that are most effective make a deliberate effort to provide food dignity through culturally appropriate and sustainable choices (Bazerghi et al., 2016; Vaterlaus et al., 2018).

\section{Food Pantry Programs Among Students of Higher Education}

\section{Target Populations and Stakeholders}

In its survey of associated food banks, the Feeding America network found that 6.0 million (14.3\%) of its clients were between the ages of 18 and 29 years old (Weinfeld et al., 2014). Over half of those were full- or part-time students, at 2.1 million and 1.1 million, respectively (Weinfeld et al., 2014). Of those students, $83.8 \%$ were food insecure and $30.5 \%$ had chosen between food and education expenses in the past year (Weinfeld et al., 2014).

\section{Organization and Design Unique to Serving Student Populations}

While many food pantry programs serve students of higher education, not all of them have services targeted or designed towards that subpopulation. The Feeding America Network found that only $14.8 \%$ of the food banks that served college students specifically provide services for students. Rather than establish programs exclusive to students, the existing programs focus on ensuring they are accessible for students (Weinfeld et al., 2014).

It is important, however, that whether existing programs reach out to students or if new programs are started to serve students, the need must be identified and the stigma of utilizing a

food pantry has to be overcome (Berry, Sloper, \& Doll, 2019). Colleges and universities may be reluctant to acknowledge the prevalence of food insecurity among their students as it can cast a negative light on a school's reputation, but this is where partnerships between the program and the faculty and staff are instrumental to draw support from the school (Berry, Sloper, \& Doll, 2019; Reppond et al, 2018; Vaterlaus et al, 2018). University-sponsored programs can have the advantage of marketing through official channels, financial support from the school, 
coordination of efforts with similarly-minded campus committees and organizations, and access to other resources such as research (Berry et al., 2019; Twill et al., 2016). 


\section{REFERENCES}

Bazerghi, C., McKay, F., \& Dunn, M. (2016). The role of food banks in addressing food insecurity: A systematic review. Journal of Community Health, 41, 732740. https://doi.org/10.1007/s10900-015-0147-5

Berry, T., Sloper, M., Doll, K. (2019) Addressing food insecurity among college students: The landscape of the feeding america network. Feeding America Network. Retrieved from https://www.feedingamerica.org/sites/default/files/201910/Feeding\%20America\%20College\%20Hunger\%20Landscape\%20\%20Full\%20Report_October\%202019.pdf

Broton, K. M., \& Goldrick-Rab, S. (2018). Going without: An exploration of food and housing insecurity among undergraduates. Educational Researcher, 47(2), 121.

Buch, K., Langley, S., Johnson, T., \& Coleman, N. (2016). A university-community partnership to combat food insecurity among college students. Partnerships, 7(1), 16.

Coleman-Jensen, A., Rabbitt, M. P., Gregory, C. A., and Singh, A. (2019). Household Food Insecurity in the United States in 2018. (Economic Research Report No. ERR-270). Washington, DC: U.S. Government Printing Office.

Creswell, J. W. (2007). Qualitative inquiry and research design: Choosing among five approaches. Thousand Oaks, CA: Sage Publications, Inc.

Dave, J. M., Thompson, D. I., Svendsen-Sanchez, A., \& Cullen, K. W. (2017). Perspectives on barriers to eating healthy among food pantry clients. Health Equity, 1(1), 28-34. 
Ellis, A., Burns, T., Buzzard, J., Dolan, L., Register, S., \& Crowe-White, K. (2017). Food insecurity among college students does not differ by affiliation in greek life. Journal of the Academy of Nutrition \& Dietetics, 117(10), A145. https://doi.org/10.1016/j.jand.2017.08.099

Gallegos, D., Ramsey, R., \& Kai, W. O. (2014). Food insecurity: Is it an issue among tertiary students? Higher Education, 67(5), 497-510. https://doi.org/10.1007/s10734-013-9656-2

Halfacre, K., Chang, Y., Roseman, M. G., \& Holben, D. (2017). Financial strain and food preparation ability may be important factors for food insecurity and fruit and vegetable consumption among university students. Journal of the Academy of Nutrition \& Dietetics, 117(9), A87. https://doi.org/10.1016/j.jand.2017.06.309

Holben, D. H., \& Marshall, M. (2017). From the academy: Position of the academy of nutrition and dietetics: Food insecurity in the united states. Journal of the Academy of Nutrition and Dietetics, 117(12), 1991-2002. https://doi.org/10.1016/j.jand.2017.09.027

Khan, F., Schiff, A., \& Mello, M. (2019). Impact of participation in the commodity supplemental food program on food insecurity among low-income elderly rhode islanders. Rhode Island Medical Journal, 102(2), 32-35.

Knol, L. L., Robb, C. A., McKinley, E. M., \& Wood, M. (2017). Food insecurity, self-rated health, and obesity among college students. American Journal of Health Education, 48(4), 248-255. https://doi.org/10.1080/19325037.2017.1316689

Knol, L., Willman, A. M., Morrison, P., Aiken, S. E., Doucet, J. E., Davis, A., . . Willard, J. C. (2017). Food insecurity is related to mindless eating practices among college students. Journal of the Academy of Nutrition \& Dietetics, 117, A87. https://doi.org/10.1016/j.jand.2017.06.378 
Lee, S. D., Hanbazaza, M., Ball, G. D. C., Farmer, A., Maximova, K., \& Willows, N. D. (2018). Food insecurity among postsecondary students in developed countries: A narrative review. British Food Journal, 120(11), 2660-2680. https://doi.org/10.1108/BFJ-08-20170450

Leung, C. W., Epel, E. S., Ritchie, L. D., Crawford, P. B., \& Laraia, B. A. (2014). Research: Food insecurity is inversely associated with diet quality of lower-income adults. Journal of the Academy of Nutrition and Dietetics, 114, 1943-1953. https://doi.org/10.1016/j.jand.2014.06.353

Maroto, M. E., Snelling, A., \& Linck, H. (2015). Food insecurity among community college students: Prevalence and association with grade point average. Community College Journal of Research and Practice, 39(6), 515-526. https://doi.org/10.1080/10668926.2013.850758.

Mirabitur, E., Peterson, K. E., Rathz, C., Matlen, S., \& Kasper, N. (2016). Predictors of collegestudent food security and fruit and vegetable intake differ by housing type. Journal of American College Health, 64(7), 555-564. https://doi.org10.1080/07448481.2016.1192543

Nguyen, B. T., Shuval, K., Bertmann, F., \& Yaroch, A. L. (2015). The supplemental nutrition assistance program, food insecurity, dietary quality, and obesity among US adults. American Journal of Public Health, 105(7), 1453. https://doi.org/10.2105/AJPH.2015.302580

O'Neill, M., \& Maguire, J. (2017). College students self-reported food insecurity and correlations with health and academic performance. Journal of Behavioral \& Social Sciences, 4(1), 3440. 
Patton-Lóez, M. M., López-Cevallos, D. F., Cancel-Tirado, D., \& Vazquez, L. (2014).

Prevalence and correlates of food insecurity among students attending a midsize rural university in oregon. Journal of Nutrition Education \& Behavior, 46(3), 209-214. https://doi.org/10.1016/j.jneb.2013.10.007

Payne-Sturges, D. C., Tjaden, A., Caldeira, K. M., Vincent, K. B., \& Arria, A. M. (2018).

Student Hunger on Campus: Food Insecurity Among College Students and Implications for Academic Institutions. American Journal of Health Promotion, 32(2), 349-354. https://doi.org/10.1177/0890117117719620

Reppond, H. A., Thomas-Brown, K., Sampson, N. R., \& Price, C. E. (2018). Addressing food insecurity in college: Mapping a shared conceptual framework for campus pantries in michigan. Analyses of Social Issues and Public Policy, 18(1), 378-399. https://doi.org/10.1111/asap.12161

Silva, M. R., Kleinert, W. L., Sheppard, A. V., Cantrell, K. A., Freeman-Coppadge, D., Tsoy, E., Roberts, T., \& Pearrow, M. (2017). The relationship between food security, housing stability, and school performance among college students in an urban university. Journal of College Student Retention: Research, Theory \& Practice, 19(3), 284-299. https://doi.org/10.1177\%2F1521025115621918

Student Government Resource Center. (2015). Running a Campus Food Pantry: Student Government Toolkit. Brandon Mathews.

Twill, S. E., Bergdahl, J., \& Fensler, R. (2016). Partnering to build a pantry: A university campus responds to student food insecurity. Journal of Poverty, 20(3), 340-358. https://doi.org/10.1080/10875549.2015.1094775 
Vaterlaus, J. M., Cottle, N. M., Patten, E. V., \& Gibbons, R. (2018). Research: Understanding customers: The jobs to be done theory applied in the context of a rural food pantry. Journal of the Academy of Nutrition and Dietetics, 118, 1895-1902.

https://doi.org/10.1016/j.jand.2018.02.011

Watson, T.D., Malan, H., Glik, D., \& Martinez, S.M. (2017). College students identify university support for basic needs and life skills as key ingredient in addressing food insecurity on campus. California Agriculture, 71(03), 130-138. https://doi.org/10.3733/ca.2017a0023

Weinfeld, N.S., Mills, G., Borger, C., Gearing, M., Macaluso, T., Montaquila, J., \& Zedlweski, S. (2014). Hunger in america 2014. Feeding America Network.

Zein, A.E., Mathews, A.E., House, L., \& Shelnutt, K.P. (2018). Why Are Hungry College Students Not Seeking Help? Predictors of and Barriers to Using an On-Campus Food Pantry. Nutrients, 10(9), 1163. https://doi.org/10.3390/nu10091163 


\section{APPENDIX A: INTERVIEW QUESTIONS}

1. What was/is your role in relation to the School Street Food Pantry?

2. What is the purpose of the School Street Food Pantry?

3. Who would you identify as key stakeholders in the School Street Food Pantry?

Why?

- Stakeholder is defined as a person with an interest or concern in the program

4. Where did the concept for the School Street Food Pantry begin?

5. What decisions were made in the development of the structure of the School Street

Food Pantry regarding the following? Why?

- User eligibility

- Funding

- Services offered

- Staffing

- Supply sources

6. What partnerships or relationships were established that were beneficial to development?

7. What partnerships do you believe would have been helpful in the beginning or even now?

8. What barriers were encountered in the development process? How do you think these could have been avoided?

9. How do you see the School Street Food Pantry fulfilling its intended purpose? 
10. How do you see the pantry falling short in its intended purpose?

11. How would you like to see the School Street Food Pantry grow or expand? Why?

12. Is there anything else you would like to share with me about the School Street

Food Pantry that I did not already ask? 